\title{
BMJ Open Work-related psychosocial risk factors for stress-related mental disorders: an updated systematic review and meta- analysis
}

Henk F van der Molen (D), Karen Nieuwenhuijsen, Monique H W Frings-Dresen, Gerda de Groene

To cite: van der Molen HF, Nieuwenhuijsen K, FringsDresen MHW, et al. Workrelated psychosocial risk factors for stress-related mental disorders: an updated systematic review and meta-analysis. BMJ Open 2020;10:e034849. doi:10.1136/ bmjopen-2019-034849

- Prepublication history and additional material for this paper are available online. To view these files, please visit the journal online (http://dx.doi. org/10.1136/bmjopen-2019034849).

HFvdM and GdG contributed equally.

Received 08 0ctober 2019

Revised 11 May 2020

Accepted 14 May 2020

\section{Check for updates}

(c) Author(s) (or their employer(s)) 2020. Re-use permitted under CC BY. Published by BMJ.

Coronel Institute of Occupational Health, Amsterdam UMC-

Locatie AMC, Amsterdam, North Holland, The Netherlands

Correspondence to Dr Henk F van der Molen;

h.f.vandermolen@

amsterdamumc.nl

\section{ABSTRACT}

Objective The objective was to conduct an update of a previously published review and meta-analysis on the association between work-related psychosocial risk factors and stress-related mental disorders (SRD). Design Systematic review and meta-analysis. Data sources Medline, Embase and PsycINF0 were searched for articles published between 2008 and 12 August 2019 and references of a systematic review performed for the period before 2008 were included. Primary prospective studies were included when outcome data were described in terms of SRD assessment or a dichotomous outcome, based on a validated questionnaire, and at least two levels of work-related exposure were reported (exposed vs less or non-exposed). We used GRADE to assess the evidence for the associations between risk factors and the onset of SRD.

Results Seventeen studies met the inclusion criteria. In total, a population of 73874 workers from Belgium, Denmark, England, Finland, Japan, the Netherlands and Sweden were included in the meta-analysis of 14 prospective cohort studies. This meta-analysis revealed moderate evidence for associations between SRD and effort reward imbalance $(\mathrm{OR}=1.9,95 \% \mathrm{Cl} 1.70$ to 2.15$)$, high job demands ( $\mathrm{OR}=1.6,95 \% \mathrm{Cl} 1.41$ to 1.72 ), organisational justice ( $0 \mathrm{Rs}=1.6$ to 1.7 , Cls 1.44 to 1.86$)$, social support ( $\mathrm{ORs}=1.3$ to 1.4 , Cls 1.16 to 1.69 ), high emotional demands (OR=1.6, $95 \% \mathrm{Cl} 1.35$ to 1.84 ) and decision authority $(\mathrm{OR}=1.3, \mathrm{Cl} 1.20$ to 1.49 ). No significant or inconsistent associations were found for job insecurity, decision latitude, skill discretion and bullying. Conclusion Moderate evidence was found that workrelated psychosocial risk factors are associated with a higher risk of SRD. Effort-reward imbalance, low organisational justice and high job demands exhibited the largest increased risk of SRD, varying from $60 \%$ to $90 \%$.

\section{INTRODUCTION}

Stress-related mental disorders (SRD) are frequently reported in the working population, with varying incidence rates of $13 \%$ for psychological distress, ${ }^{1} 22 \%$ for emotional
Strengths and limitations of this study

- This systematic review, including a meta-analysis of prospective cohort studies, gives a valuable overview in which work-related psychosocial risk factors increase the risk of stress-related mental disorders.

- The case definitions of stress-related mental disorders used validated questionnaires and the methodological quality of the included studies was high.

- The GRADE framework made it possible to assess to the quality of evidence; however, the starting level for grading this evidence for prospective aetiological studies is subject to scientific debate.

- Limitations are the lack of harmonised assessments of stress-related mental disorders and detailed exposure assessment in the identified observational cohort studies.

exhaustion $^{2}$ and a prevalence of distress symptoms of up to $50 \%$ in specific professions and countries. ${ }^{3}$ SRD represent a significant part of work-related common mental disorders in both self-report surveys and notification systems for occupational diseases. ${ }^{4}$ The WHO has recently announced ${ }^{5}$ that burn-out is included as 'an occupational phenomenon' in the 11th revision of the International Classification of Diseases (ICD-11).

In many countries, SRD are not notified as occupational diseases, ${ }^{6}$ mainly because of their multifactorial origin ${ }^{7}$ or discussion about the medical status (as with burn-out) ${ }^{589}$ Evidencebased knowledge about work-related factors could be used for facilitating a decision on the 'work-relatedness' of an individual case of SRD in a reporting scheme or concerning the selection and implementation of preventive workplace interventions around factors with the strongest effect on SRD. ${ }^{7}$

In the Netherlands, SRD cover diagnoses of adjustment disorders (ICD-10: F43.2) and burn-out as a state of exhaustion (ICD-10: 
Z730). ${ }^{4}$ These diagnoses differ from just stress symptoms since they are clinically assessed and have in common that they reflect a status where subjective and emotional disturbance interfere with social functioning and performance, arising from a period of adaptation to stressful conditions. Symptoms are what a worker experiences, and these symptoms might negatively affect normal or regular functioning of a person-a so-called disorder. To distinguish between symptoms and disorders, we considered a SRD as diagnosis following a clinical anamnesis, stress complaints as assessed in a score above a cut-off point on a validated questionnaire or absenteeism from work due to stress problems. Work-related psychosocial risk factors can contribute to the onset of SRD. ${ }^{10}$

The high and increasing burden of SRD strengthens the urgency of up-to-date insight into work-related psychosocial risk factors associated with SRD and based on longitudinal study designs in order to initiate relevant primary and secondary preventive interventions at worksites. Previous systematic reviews aiming to determine work-related risk factors for SRD have either not been updated since $2008,{ }^{10}$ combined various common mental disorders, such as anxiety, depression and stressrelated disorders, as outcome measures ${ }^{11}$ or used other outcomes, such as suicide. ${ }^{12}$ Based on seven prospective studies, Nieuwenhuijsen et $a l^{10}$ reported that high job demands, low job control, low coworker support, low supervisor support, low procedural justice, low relational justice, high effort-reward imbalance and job insecurity (only for men) predicted the occurrence of SRDs. Our aim is to update this previously published review and meta-analysis from $2008^{10}$ to examine: (1) which workrelated psychosocial risk factors contribute to the onset of SRD and (2) to what extent these risk factors are associated with SRD.

\section{METHODS}

This review followed the PRISMA Statement (see online supplementary appendix). This review was not registered in Prospero, but an update of a previous review by Nieuwenhuijsen et al. ${ }^{10}$

\section{Patient and public involvement}

There was no patient or public involvement in designing the study, but the systematic review is a response to priority setting in collaboration with policy-makers of the Dutch Ministry of Employment and Social Affairs.

\section{Study selection}

\section{Eligibility criteria}

Primary prospective cohort studies were included where outcome data were described in terms of clinically or questionnaire-assessed stress-related disorder (present or not) and at least two levels of work-related exposure (exposed vs less or non-exposed) among a working population were reported in order to be able to retrieve or calculate a risk estimate ( $\mathrm{OR}$, relative risk (RR) or $\mathrm{HR})$.
This updated systematic review ${ }^{10}$ considered studies to have included SRD if the outcome was either (i) a SRD diagnosis following a clinical anamnesis, (ii) a high level of stress complaints as assessed in a score above a cut-off point on a validated questionnaire for fatigue, stress or non-specific mental ill-health or (iii) absenteeism from work due to stress problems. Based on findings of Nieuwenhuijsen $e t a l^{10}$ and identified factors stemming from theoretical stress models, we defined seven types of exposure (i) job demands, (ii) job control (decision latitude, decision authority, skill discretion), (iii) social support (coworker, supervisor, both), (iv) emotional demands, (v) organisational justice (procedural and relational), (vi) effort-reward imbalance and (vii) other psychosocial risk factors, for example, bullying.

Studies that described work-related risk factors in terms of psychosocial risk factors were eligible for inclusion. The studies had to describe workers in a real workplace setting. All types of exposure assessment were eligible for inclusion: self-reports or researcher observations or direct measurements. No additional criteria were formulated regarding latency between exposure and the presence or onset of the disorder or adjustment for confounders.

\section{Data sources and search terms}

We searched the electronic databases of Medline, Embase and PsychInfo for studies between 2008 and 12 August 2019 as described in online supplementary appendix 1 . Our PICO can be stated as: $\mathrm{p}=$ working population, I/C exposed/less or none exposed to a priori defined exposure categories, $\mathrm{O}=$ stress related disorder. Eligible studies before 2008 were retrieved from the systematic review by Nieuwenhuijsen et al. ${ }^{10}$

\section{Data collection and analyses}

Study selection process

Titles and abstracts were independently screened by two reviewers to identify potentially relevant studies. We used a free online software tool to screen and assess references (https://rayyan.qcri.org/welcome). The full texts of potentially relevant articles were assessed for eligibility against the inclusion criteria. Disagreement between review authors on the selection of studies for inclusion occurred in less than $5 \%$ of the references screened and was resolved by discussion.

\section{Data extraction and management}

Data were extracted by one review author (GG) and checked by another review author (HM). Data on the following were extracted from each article: author, country of study, study design, case definition of stressrelated disorder, sources and number of participants, exposure definition, exposure assessment, exposure categories, risk estimate and adjustment for confounders.

\section{Methodological quality assessment}

For the assessment of the risk of bias within studies, the quality criteria from the systematic review by Nieuwenhuijsen $e t a l^{10}$ were used for all study designs, with nine items 


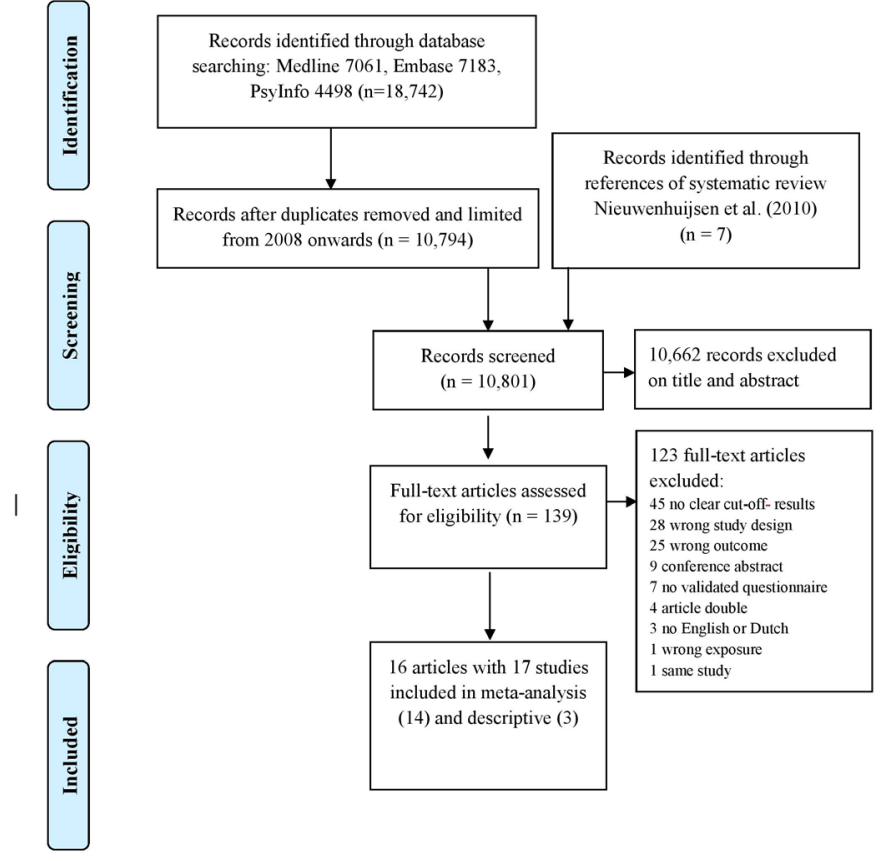

Figure 1 Prisma flow diagram.

covering the selection of participants, measurement of variables and control for confounding. The quality of the studies was independently assessed and agreed by two review authors $(\mathrm{GG}, \mathrm{HM})$. In total, nine items across five categories were evaluated for quality assessment: (1) the main features of the study population were stated, for example, sex, age and work context; (2) the participation rate at baseline was at least 50\%; (3) the response at follow-up was at least $70 \%$ or the non-response was not selective; (4) the data on psychosocial work factors were collected using standardised instruments; (5) the data on outcome were collected at least at three different time points; (6) the statistical model used was appropriate for the outcome studied; (7) the measures of association with the statistical model were presented; (8) there were study controls for confounding with rationale; (9) the number of cases was at least 10 times the number of independent variables in the analysis. The criteria for each item were scored with 'positive', 'negative' or 'not clear'. A higher quality of a study was defined as $\geq 5$ items scored as 'positive' out of the nine quality criteria.

\section{Data synthesis}

A descriptive analysis of all studies was performed, summarised, classified in categories of psychosocial risk factors and assessed for methodological quality. Risk estimates and the corresponding 95\% CI of the association between work-related factors and SRD were extracted and summarised. After assessing probable heterogeneity of risk factor and outcome assessment, all authors discussed and decided on the risk estimates to be included in the meta-analysis or should be analysed separately. We used the rule at least two studies when no statistical heterogeneity $\left(\mathrm{I}^{2}<50 \%\right)$ and no heterogeneity in measures of risk factors and stress-related disorders (as discussed among the authors) was found.
Meta-analyses and quality of evidence

The selection of the work-related risk factors in the metaanalyses was based on (1) sufficient contrast between reported exposure categories, that is, low vs high exposure; (2) effect estimates controlled for other non-work-related factors, as reported in the primary studies; (3) homogeneity in definition or measurement of risk factors.

The meta-analysis was performed in line with the procedure described in Watanabe et al: ${ }^{13}$ by using a logtransformed OR and its SE in Review Manager (Cochrane Review Manager V.5.3). For the main analysis, the main ORs and the SEs from selected studies were subjected to a random-effects model meta-analysis to estimate a pooled OR and its $95 \%$ CI.

The quality of evidence-also taken into account the risk of bias across studies-was assessed using the GRADE (Grades of Recommendations, Assessment, Development and Evaluation) framework for prognostic studies developed by Huguet $e t a l .{ }^{14}$ Following Huguet $e t a l,{ }^{14}$ our starting point for the quality of the evidence was 'moderate' for prospective cohort studies that aimed to identify associations between potential prognostic factors (in our review risk factors) and the outcome. The evidence could decrease on the basis of five factors: study limitations, inconsistency, indirectness, imprecision and publication bias. Moreover, two factors, (1) study findings with moderate or large effect sizes (ie, lower limit of 95\% CI OR $\geq 2.0$ ) or (2) an exposureresponse gradient, could lead to an upgrade of the quality of evidence. Four levels of quality were used: high, moderate, low and very low.

\section{RESULTS \\ Selected studies}

A PRISMA flow diagram of the study selection process is shown in figure 1. After excluding duplicates, 10801 references were retrieved from the databases and the systematic review by Nieuwenhuijsen $e t a l,{ }^{10}$ and assessed based on title and abstract. The full texts of 139 potentially eligible articles were then examined, of which 17 studies from 16 articles met the inclusion criteria.

\section{Psychosocial risk factors and SRD}

In total, 17 longitudinal studies in 16 articles $^{1-3}$ 15-27 described the association between exposure to psychosocial risk factors and the occurrence of assessed mental SRD. The characteristics of the outcome definition (SRD), exposure definition and reported associations are presented in table 1 .

\section{Methodological quality}

The methodological quality of the studies of risk factors varied from scoring 5 out of 9 items to 8 out of 9 items (see table 2). The most frequently missing quality items were response at follow-up less $70 \%$, data on outcome were collected at least at three different time points and study controls for confounding with rationale. 
Table 1 Associations between psychosocial risk factors at work and the occurrence of mental stress related disorders (17 studies)

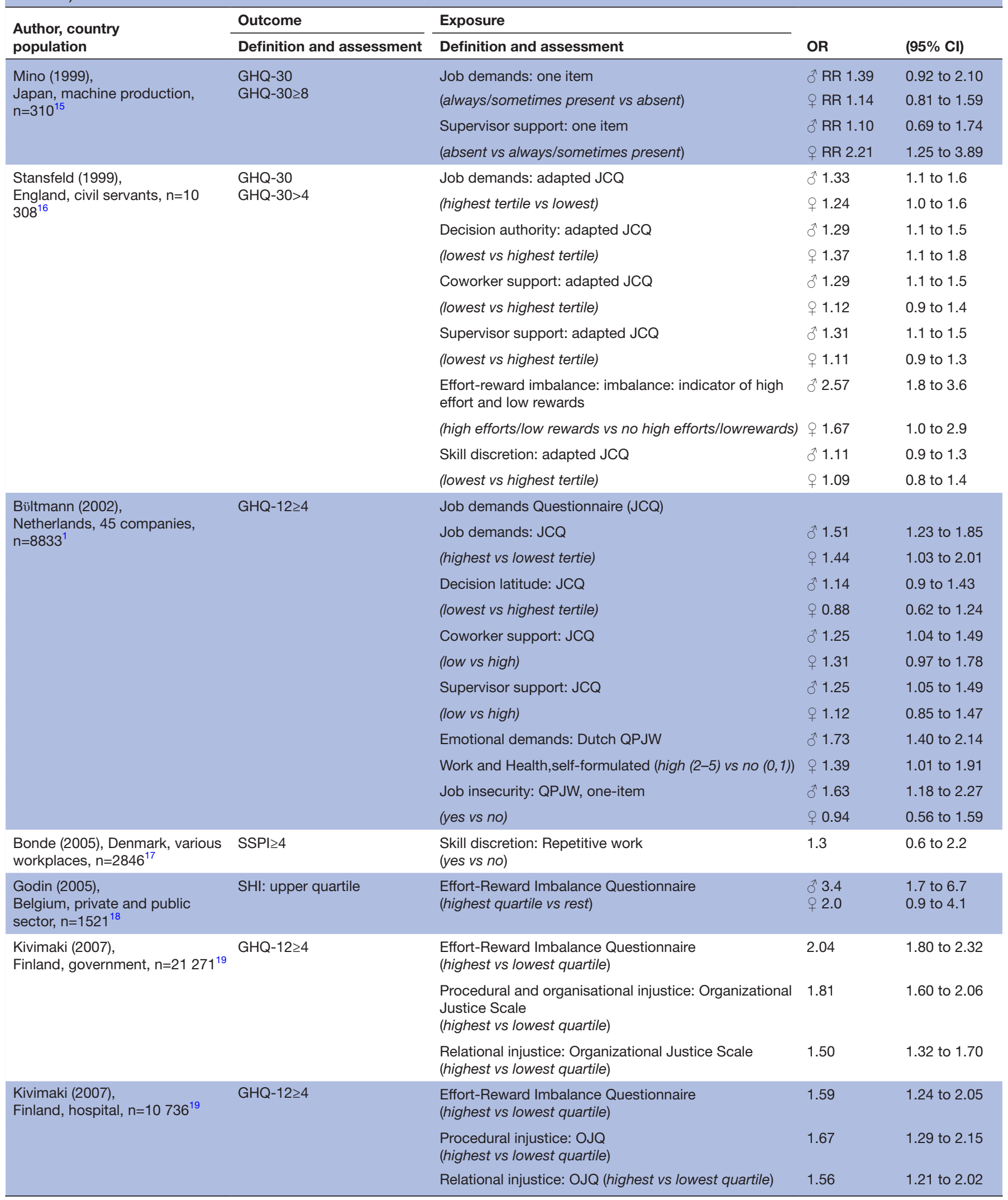

Continued 
Table 1 Continued

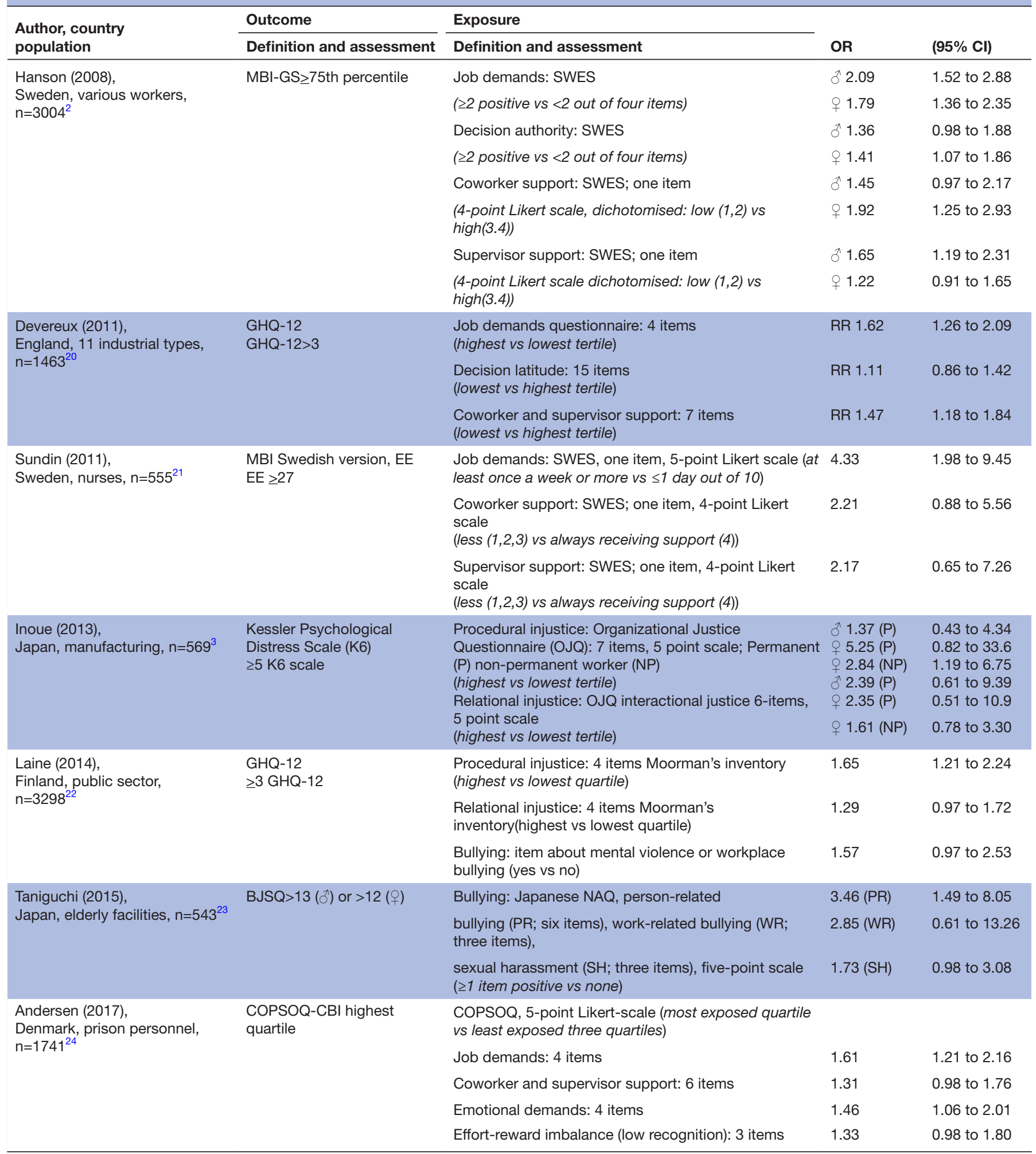

Continued 
Table 1 Continued

\begin{tabular}{|c|c|c|c|c|}
\hline \multirow{2}{*}{$\begin{array}{l}\text { Author, country } \\
\text { population }\end{array}$} & \multirow{2}{*}{$\begin{array}{l}\text { Outcome } \\
\text { Definition and assessment }\end{array}$} & \multirow{2}{*}{$\begin{array}{l}\text { Exposure } \\
\text { Definition and assessment }\end{array}$} & \multirow[b]{2}{*}{ OR } & \multirow[b]{2}{*}{$(95 \% \mathrm{Cl})$} \\
\hline & & & & \\
\hline \multirow{6}{*}{$\begin{array}{l}\text { Oshio (2017), } \\
\text { Japan, } 12 \text { industrial types, } \\
n=7419^{25}\end{array}$} & \multirow{6}{*}{$\begin{array}{l}\text { Kessler Psychological } \\
\text { Distress Scale (K6) } \\
\text { K6 } \geq 5\end{array}$} & Job demands: 5 items Japanese JCQ, 4- & 1.62 & 1.45 to 1.81 \\
\hline & & Procedural injustice: Japanese version of & 01.68 & 1.51 to 1.87 \\
\hline & & OJQ, 7 items, 5-point Likert scale & 우 1.80 & 1.45 to 2.23 \\
\hline & & OJQ, 6 items, 5-point Likert scale & 우 1.71 & 1.37 to 2.13 \\
\hline & & $\begin{array}{l}\text { Effort reward imbalance: Japanese version Effort- } \\
\text { Reward Imbalance }\end{array}$ & 2.05 & 1.84 to 2.29 \\
\hline & & $\begin{array}{l}\text { Questionnaire, effort (three items), reward (seven } \\
\text { items), 4-point scale }\end{array}$ & ㅇ 1.84 & 1.48 to 2.28 \\
\hline
\end{tabular}

BJSQ, Brief Job Stress Questionnaire; BOSS, Burnout screening scales; CBI, Copenhagen Burnout Inventory; COPSOQ, Copenhagen Psychosocial Questionnaire; EE, Emotional Exhaustion; GHQ, General Health Questionnaire; JCQ, Job Content Questionnaire; MBI, Maslach Burnout Inventory; MBI-GS, Maslach Burnout Inventory-General Survey; NAQ, Negative Acts Questionnaire; OJQ, Organizational Justice Questionnaire ; QPJW, Questionnaires; Perception and Judgement of Work; RR, relative risk; SHI, Short Fatigue Inventory; SSPI, Setterlind Stress Profile Inventory; SWES, Swedish Work Environment Survey.

\section{Meta-analyses and assessment of evidence}

In total, 12 psychosocial risk factors from 14 studies $^{1-3} 15-222425$ from a population of 73874 workers from Belgium, Denmark, England, Finland, Japan, Netherlands and Sweden were used in the meta-analysis. Reported distress prevalence varied from $4.9 \%{ }^{17}$ to $45.8 \%{ }^{3}$ The follow-up time varied from 1 to 5 years. Table 3 summarises the assessment of evidence concerning the psychosocial risk factors for stress-related disorders.

\section{Effort-reward balance}

Six cohort studies ${ }^{16} 18192425$ demonstrate that there is moderate-quality evidence that effort-reward imbalance increases the incidence of SRD, with a pooled OR of 1.91 (95\% CI 1.70 to 2.15 ) (see table 3 and figure 2). No statistically significant difference between subgroups of men and women was found. ${ }^{161825}$

\section{Procedural and relational justice}

Five cohort studies ${ }^{3} 192225$ demonstrate that there is moderate-quality evidence that low procedural justice with a pooled OR of 1.73 (95\% CI 1.61 to 1.86 ) and low relational justice with a pooled OR of 1.55 (95\% CI 1.44 to 1.67) increase the incidence of SRD (see table 3 and figure 3). No statistically significant difference between subgroups of men and women was found. ${ }^{325}$

\section{Job demands}

Eight cohort studies ${ }^{1} 2151620212425$ demonstrate that there is moderate-quality evidence that high job demands increase the incidence of SRD, with a pooled OR of 1.55 (95\% CI 1.41 to 1.71 ) (see table 3 and figure 4 ). No statistically significant difference between subgroups of men and women was found. ${ }^{12151625}$

\section{Coworker and supervisor support}

In total, five cohort studies demonstrate that there is moderate-quality evidence that low coworkers support $^{121621}$ with a pooled OR 1.29 (95\% CI 1.17 to 1.43 ) and low supervisor support ${ }^{12151621}$ with a pooled OR 1.27 (95\% CI 1.14 to 1.40) increase the incidence of SRD. No statistically significant difference between subgroups of men and women was found. ${ }^{121516}$ The combination of low coworker and supervisor support ${ }^{2024}$ resulted in a pooled OR 1.41 (95\% CI 1.18 to 1.69 ) (see table 3 ).

\section{Emotional demands}

Two cohort studies ${ }^{124}$ demonstrate that there is moderatequality evidence that high emotional demands increase the incidence of SRD, with a pooled OR of $1.58(95 \%$ CI 1.35 to 1.84 ) (see table 3 ). No statistically significant difference between men and women was found in the study of Bültmann et al. ${ }^{1}$

\section{Decision authority}

Two cohort studies ${ }^{216}$ demonstrate that there is moderatequality evidence that low decision autonomy increases the incidence of SRD with a pooled OR of 1.34 (95\% CI 1.20 to 1.49 ) (see table 3 ). No statistically significant difference between subgroups of men and women was found.

\section{Job security, decision latitude, skill discretion and bullying}

One cohort study ${ }^{1}$ demonstrates that there is low-quality evidence that job insecurity increases the incidence of 
Table 2 Methodological quality scores of 9 items for studies regarding risk factors*

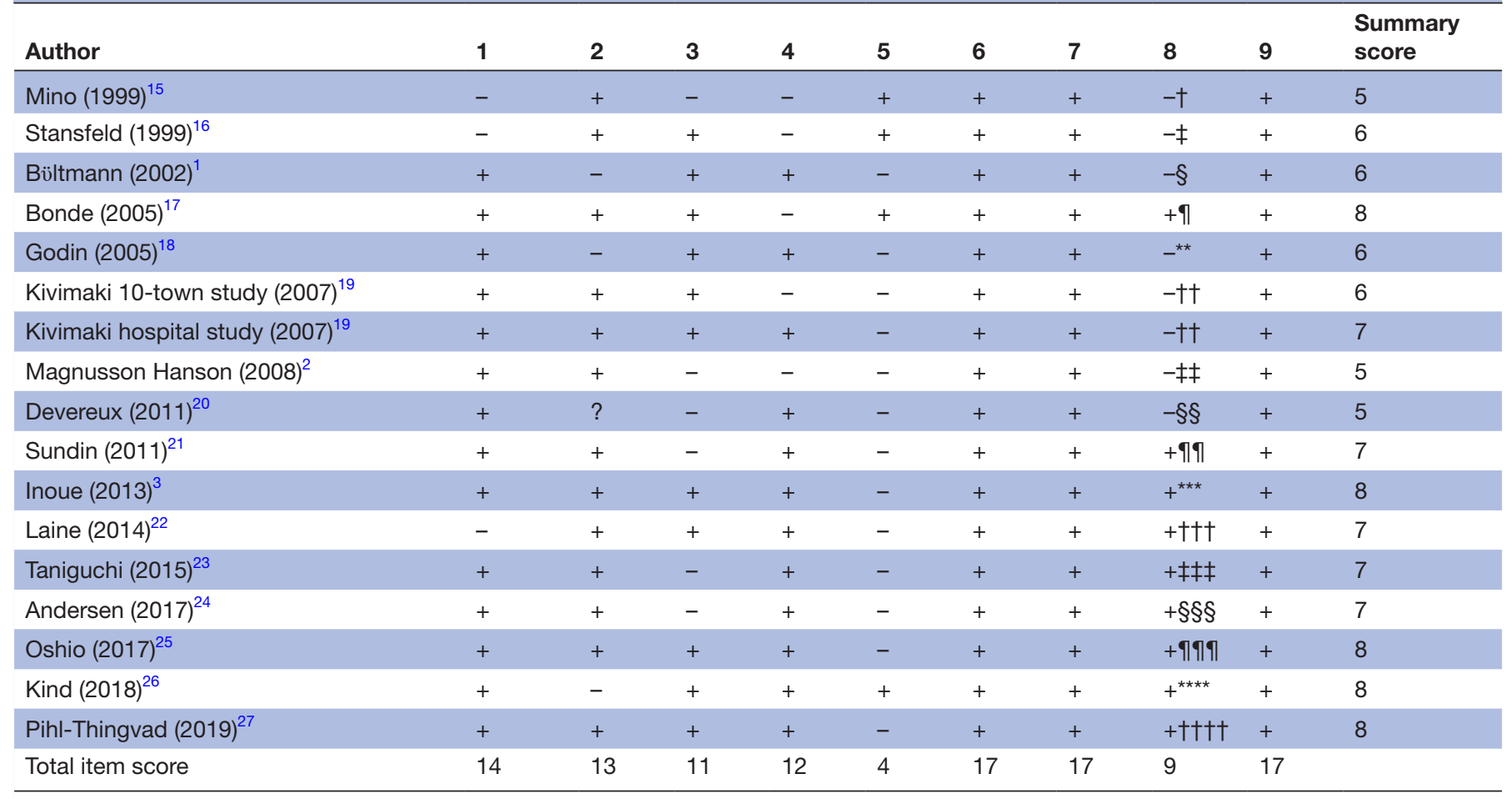

${ }^{*}$ Criteria and scoring options for quality score for these nine items are reported in the Methods section.

†Adjusted for age, sex, family life satisfaction, perceived physical health.

$\ddagger$ Adjusted for age, sex, employment grade and baseline GHQ score.

$\S$ Adjusted for age, sex, education, living alone, employment status, presence of disease, baseline fatigue score.

ПAdjusted for age, sex, body mass index, leisure time activity, pain threshold, marital status, psychiatric disorder.

**Adjusted for age, sex, education, threat from global economy, job dissatisfaction, workplace instability.

††Adjusted for age, sex, occupational status.

$\ddagger \ddagger$ Adjusted for age, sex, marital status, country of birth, social class, physical exhaustion.

$\S \S$ Adjusted for age, sex, shift work.

११Adjusted for age, sex, marital status, years of (current) employment (only for job demands).

${ }_{* \star \star}$ Adjusted for age, sex, education, marital status, chronic physical diseases, occupation, life events, neuroticism.

†††Adjusted for age, sex, socioeconomic position, marital status, employment, health behaviour, limiting longstanding illness, physical work.

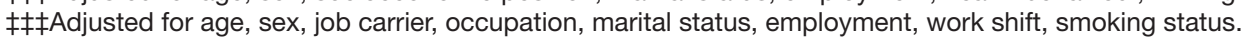

$\S \S \S A d j u s t e d$ for age, sex, marital status, employment years, occupational characteristics and exposures.

ๆๆๆAdjusted for age, sex, education, occupation, hours worked per week, household income, family member to share living expenses, firm codes.

${ }^{* \star \star \star A d j u s t e d ~ f o r ~ a g e, ~ s e x, ~ w o r k ~ e x p e r i e n c e, ~ e m p l o y m e n t ~ y e a r s, ~ p r i v a t e ~ s t r e s s o r s . ~}$

$\dagger+\dagger \dagger$ Adjusted for age, sex, somatic and mental health at baseline, lifestyle factors, work-related factors.

GHQ, General Health Questionnaire.

SRD, with a pooled OR of 1.63 (95\% CI 1.18 to 2.27 ) for male and no increase of the incidence for female with a pooled OR of 0.94 (95\% CI 0.56 to 1.59 ).

Two cohort studies ${ }^{1}{ }^{20}$ demonstrate that there is moderate-quality evidence for no increased incidence of SRD due to low decision latitude, with an OR of 1.07 (95\% CI 0.92 to 1.25$)$. Two cohort studies ${ }^{16}{ }^{17}$ demonstrate that there is moderate-quality evidence for no increased incidence of SRD due to low skill discretion, with an OR of 1.11 (95\% CI 0.94 to 1.32 ). Four cohort studies $^{22} 232627$ demonstrate very low-quality evidence that there is inconsistent evidence for increased incidence of SRD with different types of bullying and workplace violence with ORs varying from 1.42 (95\% CI 0.42 to 4.79 ) to 3.64 (95\% CI 0.83 to 15.92 ) (see table 3 ). Laine $e t$ $a l^{22}$ studied workplace bullying or mental violence as the isolation of a member of the organisation, the underestimation of work performance, being threatened, being talked about behind one's back or other forms of pressure. Taniguchi et $a l^{23}$ studied person-related bullying, workplace bullying and sexual harassment. Kind $e t a l^{26}$ studied verbal and physical client aggression and PhilThingvad $e t a l^{27}$ studied physical violence.

\section{DISCUSSION \\ Main findings}

This systematic review, including a meta-analysis of prospective cohort studies revealed moderate-quality evidence that effort-reward imbalance, low procedural and relational justice, high job demands, low coworker and supervisor support, high emotional demands and low decision authority increase the incidence of stressrelated disorders, varying from $20 \%$ to $90 \%$. Low-quality evidence was found for an association between job insecurity and stress-related disorder among men. Moderate 


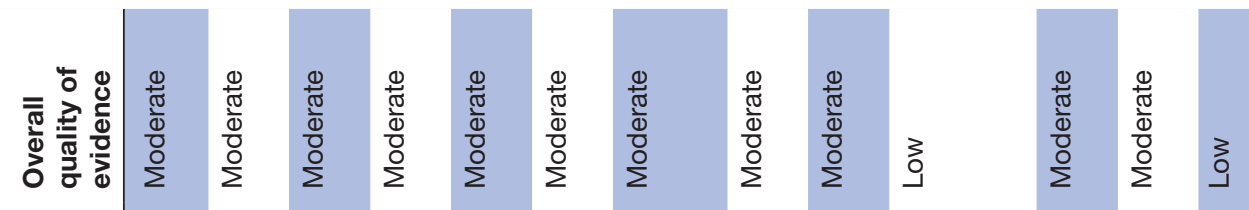

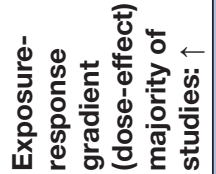

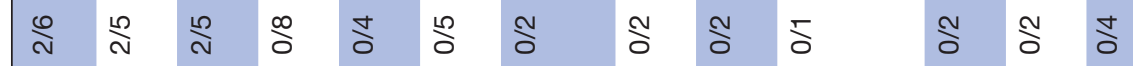

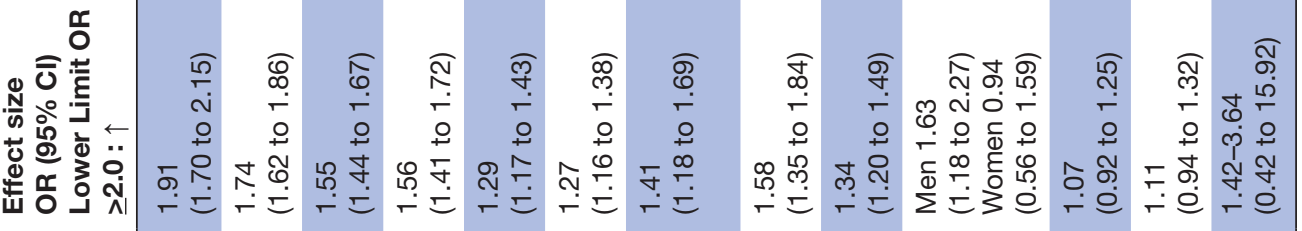

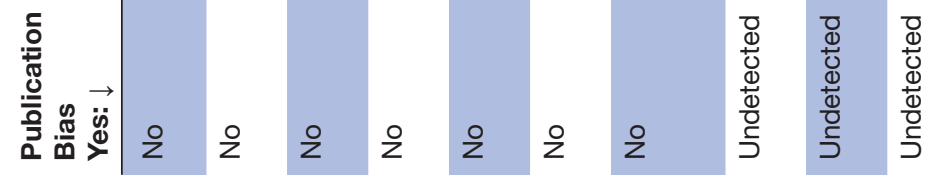
을 $\frac{\mathbb{N}}{\mathrm{N}}$

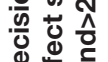

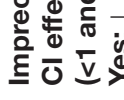

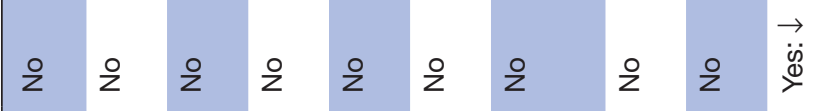

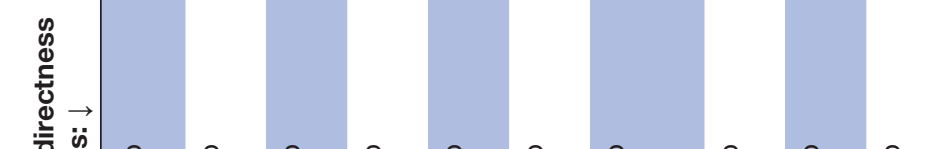

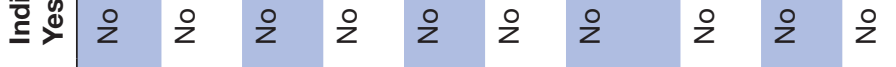
>气

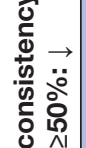
○.

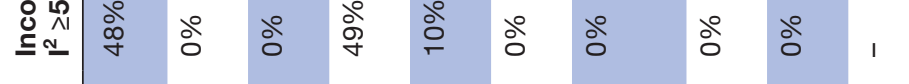

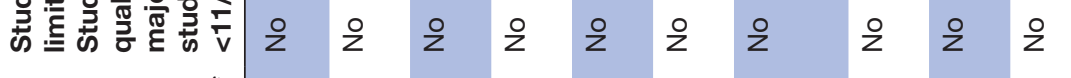
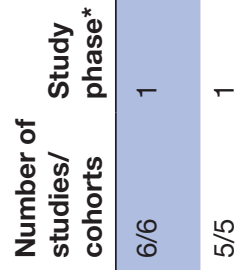

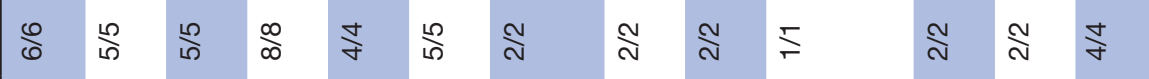

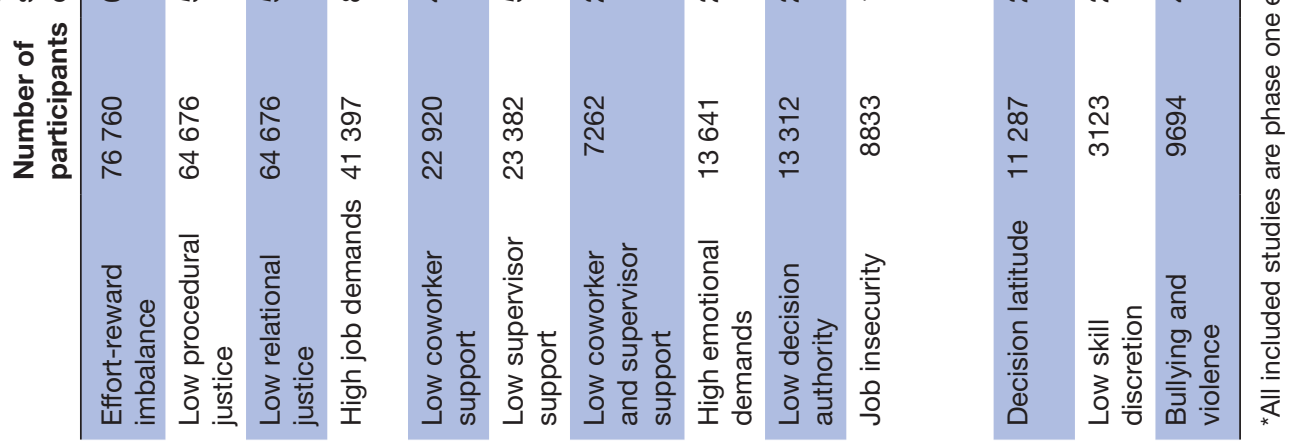




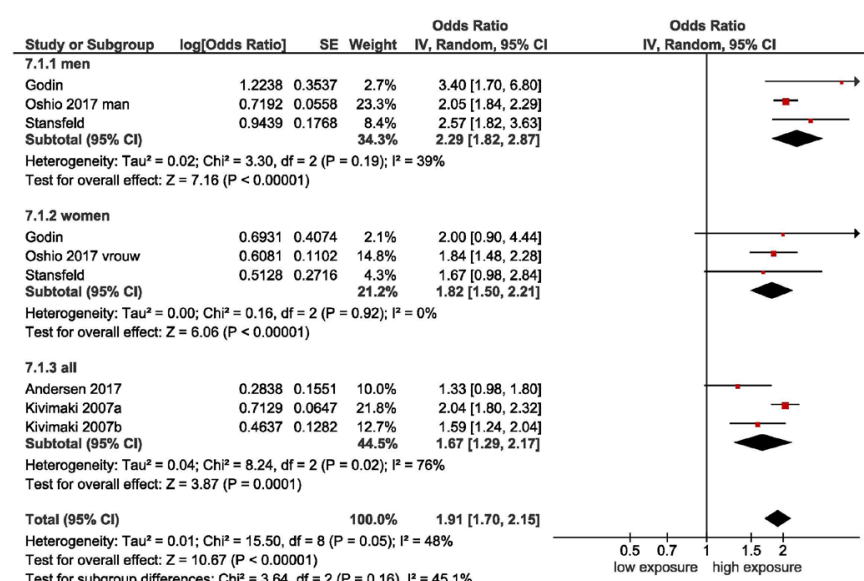

Figure 2 Forest plot of studies regarding effort-reward imbalance and SRD. SRD, stress-related mental disorders.

to low-quality evidence suggesting no associations were found for decision latitude, skill discretion and bullying.

\section{Psychosocial risk factors and SRD}

All prospective cohort studies were controlled for the personal factors of age and sex and non-work-related factors such as education and marital status. Six studies also controlled for other work-related psychosocial risk factors in various models. ${ }^{3} 19202227$ Regarding these studies, we decided not to take into account the fully adjusted model in the meta-analyses in order to avoid overcorrection and strengthen transparency and comparability between studies. However, these models yielded small and non-statistically significant differences between the risk estimates.

All studies defined SRD based on self-report with validated and standardised questionnaires, that is, (shortened) GHQ, ${ }^{1516192022}$ Kessler 6, ${ }^{325}$ Maslach Burnout Inventory, $^{21}$ Copenhagen Psychosocial QuestionnaireCopenhagen Burnout Inventory, ${ }^{24} 27$ Setterlind Stress Inventory Profile, ${ }^{17}$ fatigue inventory, ${ }^{18}$ Brief Job Stress Questionnaire ${ }^{27}$ and burnout screening scale. ${ }^{26}$

The pooled ORs of the meta-analyses of psychosocial risk factors were equal or slightly raised compared with the prior results of Nieuwenhuijsen $e t a l^{10}$ and in line with the findings of a recent meta-review of work-related risk

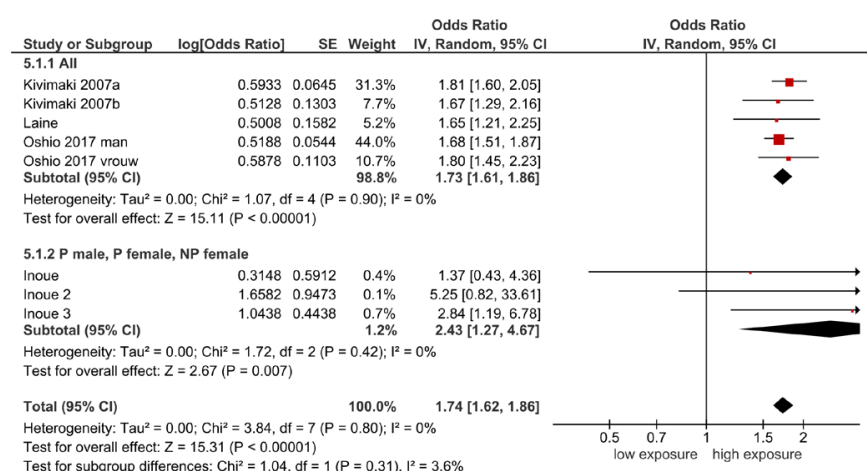

Figure 3 Forest plot of studies regarding procedural injustice and SRD. SRD, stress-related mental disorders.

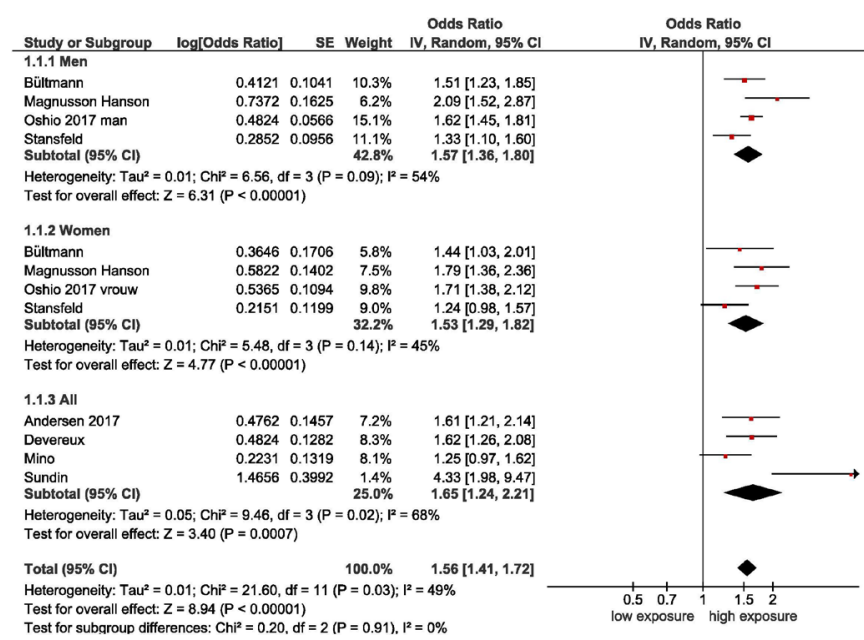

Figure 4 Forest plot of studies regarding job demands and SRD. SRD, stress-related mental disorders.

factors for common mental-health problems including depression and anxiety. ${ }^{11}$

\section{Methodological considerations}

The exposure categories for the risk factors and the case definitions of SRD varied in the included studies. We have explicitly described all definitions and assessments of selfreported exposures and outcomes (see table 1). In general, psychological distress can stem from private life as well as from work. Therefore, we only included high-quality prospective studies aimed at identifying work-related risk factors, also controlling for other factors outside the work context. Although there is debate about the definition of burnout, ${ }^{5728}$ we regarded distress and burnout as outcomes of the same continuum. We found that similar work-related psychosocial risk factors were associated with distress and the one-dimensional measures of burn-out ('exhaustion'). Should more studies using the multiple dimension definition of burnout become available, then subgroup analyses of these studies can be performed to assess whether the work-related risk factors are similar in this diagnostic subgroup.

We used the risk estimates-mostly ORs-as reported in the original prospective cohort studies (see also table 1). Meta-analyses were performed to estimate pooled associations, although the variety in measurement instruments and dichotomisation rules introduced heterogeneity in the outcome measures (case definitions) and exposure categories of psychosocial risk factors. However, the exposure categories for the psychosocial risk factors included in the meta-analyses were already established in theoretical models of effort-reward imbalance, ${ }^{29}$ job demandscontrol $^{30}$ and organisational justice. ${ }^{31}$ Furthermore, the case definitions of SRD used validated questionnaires and the methodological quality of the included studies was high and accompanied by a low to moderate statistical heterogeneity across the pooled studies $\left(\mathrm{I}^{2}\right.$ varying from $0 \%$ to $49 \%$ ) which justify the meta-analyses. With the low number of studies for each risk factor, we feel that more subgroup analyses-besides the meta-analyses for separate 
risk factors and sexes-are not informative. Reporting bias is a concern because both psychosocial factors and SRD are self-reported in the included studies; it is conceivable that certain psychological states at baseline are associated both with the over-reporting of adverse working conditions at baseline and with the risk of onset of stress related disorders at follow-up. ${ }^{32}$ In prospective studies, this risk is less pronounced $;^{33}$ however, in only 4 out 17 prospective studies in this systematic review, data on outcome were collected at least at three different time points.

The GRADE framework made it possible to assess to the quality of evidence in reviews of prognostic factor research. However, the starting level for grading of the evidence for prospective aetiological studies is subject to scientific debate. For intervention studies, the grading of observational studies starts with low evidence. For prospective observational studies, which can answer prognostic, or as in our systematic review, aetiological research questions, Huguet $e t$ $\mathrm{al}^{14}$ suggest that higher levels of evidence are derived from cohort studies that seeks to confirm independent associations between the prognostic factor and the outcome (high level of evidence) or-as in our systematic review-aimed to identify associations between potential prognostic factors and the outcome (moderate level of evidence). Also, recent GRADE guidelines state that best evidence regarding prognostic factors usually originates from observational studies (eg, cohort studies or registries), while randomised control trials could include restrictions that exclude subjects relevant for the assessment of prognostic factors. ${ }^{34}$

Based on Huguet et al, ${ }^{14}$ we classified the risk of publication bias as 'no bias' when the value of the risk factor in predicting the outcome has been repetitively investigated in explanatory studies. We provided no funnel plots because the number of cohort studies for each psychosocial risk factor was substantially lower than 10 . Visually checking the funnel plots, however, suggested no serious publication bias or could not assessed (undetected publication bias).

For the risk factor, bullying and violence, it was decided not to perform a meta-analysis because of the different concepts of the psychosocial risk factor, that is, personrelated bullying, work-related bullying, sexual harassment, workplace bullying, threatening or violence.

Eventually, further research in harmonising the assessment of SRD in cohort studies ${ }^{7}$ and the clinical assessment with signs and symptoms of SRD, ${ }^{35}$ combined with more detailed or objective task-based exposure assessment ${ }^{36}$ will contribute to a better insight into the workrelated psychosocial risk factors and their mediating or moderating factors.

\section{Prevention}

To manage and prevent stress disorders, it is necessary to identify which psychosocial risk factors at work contribute to the onset of SRD. West $e t a l^{37}$ describe the importance of organisational strategies in their review on interventions to prevent and reduce SRD among physicians. Kalani et $a l^{8}$ report in their meta-review that various studies of the effectiveness of individually and organisationally directed interventions have led to different results on reducing physician burnout. Ultimately, to develop individually and organisationally directed interventions, it is necessary that the relevant psychosocial risk factors in organisations are known. ${ }^{3738}$

Recently, Fan $e t a l^{39}$ have suggested that some psychosocial factors such as job control, job security and social support are also associated with a greater likelihood of workers' experiencing positive mental well-being in terms of satisfaction and purpose in life, personal growth, social contribution and integration. This study implicates the double value of workplace policies and practices that improve psychosocial working conditions, reduce workrelated SRD and improve mental well-being in general, for example, by giving workers greater job control or social support. ${ }^{39}$

In conclusion, several psychosocial work-related risk factors for SRD were established, confirming the multifactorial aetiology of SRD. Effort-reward imbalance, low organisational justice and high job demands were associated with the largest increased risk of SRD, varying from $60 \%$ to $90 \%$. Awareness of these risk factors could be the starting point for the selection of preventive interventions to reduce work-related SRD.

Acknowledgements We are very grateful to Joost Daams for his contribution to the literature search and Nicolaas Kylstra and Kim van der Molen for their help with screening activities.

Contributors HFvdM and GdG initiated the study, performed data extraction and statistical analyses and drafted the manuscript. All authors performed the study selection and interpretation of the data. All authors made substantial contributions to the conception of the study and manuscript.

Funding The work was sponsored by the Ministry of Social Affairs and Employment, the Netherlands. Grant number: 5100-24108

Competing interests None declared.

Patient consent for publication Not required.

Provenance and peer review Not commissioned; externally peer reviewed.

Data availability statement All data relevant to the study are included in the article or uploaded as supplementary information

Open access This is an open access article distributed in accordance with the Creative Commons Attribution 4.0 Unported (CC BY 4.0) license, which permits others to copy, redistribute, remix, transform and build upon this work for any purpose, provided the original work is properly cited, a link to the licence is given, and indication of whether changes were made. See: https://creativecommons.org/ licenses/by/4.0/.

ORCID iD

Henk F van der Molen http://orcid.org/0000-0002-0719-2020

\section{REFERENCES}

1 Bültmann U, Kant IJ, Van den Brandt PA, et al. Psychosocial work characteristics as risk factors for the onset of fatigue and psychological distress: prospective results from the Maastricht cohort study. Psychol Med 2002;32:333-45.

2 Magnusson Hanson LL, Theorell T, Oxenstierna G, et al. Demand, control and social climate as predictors of emotional exhaustion symptoms in working Swedish men and women. Scand J Public Health 2008;36:737-43.

3 Inoue A, Kawakami N, Tsuno K, et al. Organizational justice and psychological distress among permanent and non-permanent employees in Japan: a prospective cohort study. Int J Behav Med 2013;20:265-76. 
4 van der Molen HF, de Vries S, Sluiter JK. Occupational diseases among workers in lower and higher socioeconomic positions. Int $J$ Environ Res Public Health 2018;15:2849.

5 WHO. Burn-out an "occupational phenomenon": international classification of diseases what are social determinants of health? 2019 Available: https://www.who.int/mental_health/evidence/burn-out/en/? mc_cid=c8878361fa\&mc_eid=8d4606394a [Accessed 6 Aug 2019].

6 Lastovkova A, Carder M, Rasmussen HM, et al. Burnout syndrome as an occupational disease in the European union: an exploratory study. Ind Health 2018;56:160-5.

7 Canu I, Bianchi R, Bubas M, et al. Which factors contribute to the onset of burnout among workers? A systematic review, 2018. Available: http://www.crd.york.ac.uk/PROSPERO/display_record. php?ID=CRD42018105901

8 Chirico F. [ls burnout a syndrome or an occupational disease? Instructions for occupational physicians]. Epidemiol Prev 2017;41:294-8

9 Chirico $\mathrm{F}$. The forgotten realm of the new and emerging psychosocial risk factors. J Occup Health 2017;59:433-5.

10 Nieuwenhuijsen K, Bruinvels D, Frings-Dresen M. Psychosocial work environment and stress-related disorders, a systematic review. Occup Med 2010;60:277-86.

11 Harvey SB, Modini M, Joyce S, et al. Can work make you mentally ill? A systematic meta-review of work-related risk factors for common mental health problems. Occup Environ Med 2017;74:301-10.

12 Milner A, Witt K, LaMontagne AD, et al. Psychosocial job stressors and suicidality: a meta-analysis and systematic review. Occup Environ Med 2018:75:245-53.

13 Watanabe K, Imamura K, Kawakami N. Working hours and the onset of depressive disorder: a systematic review and meta-analysis. Occup Environ Med 2016;73:oemed-2016-103845.

14 Huguet A, Hayden JA, Stinson J, et al. Judging the quality of evidence in reviews of prognostic factor research: adapting the GRADE framework. Syst Rev 2013;2:71.

15 Mino Y, Shigemi J, Tsuda T, et al. Perceived job stress and mental health in precision machine workers of Japan: a 2 year cohort study. Occup Environ Med 1999;56:41-5.

16 Stansfeld SA, Fuhrer R, Shipley MJ, et al. Work characteristics predict psychiatric disorder: prospective results from the Whitehall II study. Occup Environ Med 1999;56:302-7.

17 Bonde JP, Mikkelsen S, Andersen JH, et al. Understanding work related musculoskeletal pain: does repetitive work cause stress symptoms? Occup Environ Med 2005;62:41-8.

18 Godin I, Kittel F, Coppieters Y, et al. A prospective study of cumulative job stress in relation to mental health. BMC Public Health 2005;5:67.

19 Kivimäki M, Vahtera J, Elovainio M, et al. Effort-reward imbalance, procedural injustice and relational injustice as psychosocial predictors of health: complementary or redundant models? Occup Environ Med 2007;64:659-65.

20 Devereux JJ, Rydstedt LW, Cropley M. Psychosocial work characteristics, need for recovery and musculoskeletal problems predict psychological distress in a sample of British workers. Ergonomics 2011;54:840-8.

21 Sundin L, Hochwälder J, Lisspers J. A longitudinal examination of generic and occupational specific job demands, and work-related social support associated with burnout among nurses in Sweden. Work 2011:38:389-400.
22 Laine H, Saastamoinen P, Lahti J, et al. The associations between psychosocial working conditions and changes in common mental disorders: a follow-up study. BMC Public Health 2014;14:588.

23 Taniguchi T, Takaki J, Hirokawa K, et al. Associations of workplace bullying and harassment with stress reactions: a two-year follow-up study. Ind Health 2016;54:131-8.

24 Andersen DR, Andersen LP, Gadegaard CA, et al. Burnout among Danish prison personnel: a question of quantitative and emotional demands. Scand J Public Health 2017:45:824-30.

25 Oshio T, Inoue A, Tsutsumi A. Examining the mediating effect of work-to-family conflict on the associations between job stressors and employee psychological distress: a prospective cohort study. BMJ Open 2017;7:e015608.

26 Kind N, Eckert A, Steinlin C, et al. Verbal and physical client aggression - a longitudinal analysis of professional caregivers' psychophysiological stress response and burnout. Psychoneuroendocrinology 2018;94:11-16.

27 Pihl-Thingvad J, Elklit A, Brandt LPA, et al. Workplace violence and development of burnout symptoms: a prospective cohort study on 1823 social educators. Int Arch Occup Environ Health 2019:92:843-53.

28 Maslach C, Leiter MP. Understanding the burnout experience: recent research and its implications for psychiatry. World Psychiatry 2016;15:103-11

29 Siegrist J, Siegrist K, Weber I. Sociological concepts in the etiology of chronic disease: the case of ischemic heart disease. Soc Sci Med 1986;22:247-53

30 Karasek RA. Job demands, job decision latitude, and mental strain: implications for job redesign. Adm Sci Q 1979;24:285-308.

31 Moorman $\mathrm{RH}$. Relationship between organizational justice and organizational citizenship behaviors: do fairness perceptions influence employee citizenship? J Appl Psychol 1991;76:845-55.

32 Rugulies R, Aust B, Madsen IE. Effort-reward imbalance at work and risk of depressive disorders. A systematic review and metaanalysis of prospective cohort studies. Scand J Work Environ Health 2017;43:294-306.

33 Theorell T, Hammarström A, Aronsson G, et al. A systematic review including meta-analysis of work environment and depressive symptoms. BMC Public Health 2015;15:738.

34 Foroutan F, Guyatt G, Zuk V, et al. GRADE guidelines 28: use of grade for the assessment of evidence about prognostic factors: rating certainty in identification of groups of patients with different absolute risks. J Clin Epidemiol 2020;121:62-70.

35 Kakiashvili T, Leszek J, Rutkowski K. The medical perspective on burnout. Int J Occup Med Environ Health 2013;26:401-12.

36 Göras C, Olin K, Unbeck M, et al. Tasks, multitasking and interruptions among the surgical team in an operating room: a prospective observational study. BMJ Open 2019;9:e026410.

37 West CP, Dyrbye LN, Erwin PJ, et al. Interventions to prevent and reduce physician burnout: a systematic review and meta-analysis. Lancet 2016;388:2272-81.

38 Kalani SD, Azadfallah P, Oreyzi $\mathrm{H}$, et al. Interventions for physician burnout: a systematic review of systematic reviews. Int J Prev Med 2018;9:81.

39 Fan JK, Mustard C, Smith PM. Psychosocial work conditions and mental health: examining differences across mental illness and wellbeing outcomes. Ann Work Expo Health 2019;63:546-59. 